\title{
Attitudinal Analyses of Toleration and Respect and the Problem of Institutional Applicability
}

\section{Lægaard, Sune}

Published in:

European Journal of Philosophy

DOI:

10.1111/ejop. 12027

Publication date:

2015

Document Version

Early version, also known as pre-print

Citation for published version (APA):

Lægaard, S. (2015). Attitudinal Analyses of Toleration and Respect and the Problem of Institutional Applicability. European Journal of Philosophy, 23(4), 1064-1081. https://doi.org/10.1111/ejop.12027

\section{General rights}

Copyright and moral rights for the publications made accessible in the public portal are retained by the authors and/or other copyright owners and it is a condition of accessing publications that users recognise and abide by the legal requirements associated with these rights.

- Users may download and print one copy of any publication from the public portal for the purpose of private study or research.

- You may not further distribute the material or use it for any profit-making activity or commercial gain.

- You may freely distribute the URL identifying the publication in the public portal.

\section{Take down policy}

If you believe that this document breaches copyright please contact rucforsk@kb.dk providing details, and we will remove access to the work immediately and investigate your claim. 


\title{
Attitudinal Analyses of Toleration and Respect, and the Problem of
}

\author{
Institutional Applicability ${ }^{1}$
}

\section{Sune Lægaard}

Abstract: Toleration and respect are types of relations between different agents. The standard analyses of toleration and respect are attitudinal; toleration and respect require subjects to have appropriate types of attitudes towards the objects of toleration or respect. The paper investigates whether states can sensibly be described as tolerant or respectful in ways theoretically relevantly similar to the standard analyses. This is a descriptive question about the applicability of concepts rather than a normative question about whether, when and why states should be tolerant or respectful. The problem of institutional application is that institutions in general and the state in particular arguably cannot have attitudes of the required kind. This problem is distinct from, and broader than, well known problems about whether political toleration is normatively legitimate. To make sense of political toleration or respect, the paper proposes that the analysis of institutional toleration and respect should not be solely agent-centred (as in attitudinal analyses) or patientcentred (as in explanations of the good of toleration or respect in terms of the effects of being tolerated or respected). The analysis should also include features about the relation itself. We can describe institutions as tolerant or respectful in a sense relevantly similar to the standard analyses if we focus on the public features of the relation between institutions and citizens or groups, without ascribing attitudes in the problematic sense.

\footnotetext{
${ }^{1}$ The final version of this paper has been published in the European Journal of Philosophy, Early View online publication 16 APR 2013, DOI: 10.1111/ejop.12027

Link to published paper: http://onlinelibrary.wiley.com/doi/10.1111/ejop.12027/abstract
} 


\section{Introduction}

Consider some examples of relations between states and citizens: A state engages in public health policies including public campaigns against certain life-style choices, e.g. smoking, drinking, not exercising, eating fat foods, and impose extra taxes on the related products. The state also has some form of established religion so that, even though other religious groups are granted freedom of religion, a particular religion is privileged above the rest. The state rejects some applications for asylum but nevertheless grants exceptional leave to remain to some rejected applicants. While the state no longer criminalises homosexuality, homosexuals are not treated equally - they can for instance not be married on the same terms as heterosexual couples. Finally, the state still has a clause in its penal code criminalising blasphemy, but this is in practice dormant and never enforced.

Homosexuality is no longer outlawed, and the state refrains from outright banning smoking and similar unhealthy life style choices, because it considers all citizens equal and as themselves responsible for their way of life. While the blasphemy clause is kept on the books to signal disapproval of hate-speech against religious minorities, it is not enforced because of the importance of free speech.

Now consider a liberal reform, after which the state drops paternalist health policies, extends the same rules of marriage to hetero- and homosexuals, and disestablishes the state church, thereby placing all religions on an equal footing in relation to the state.

How should these cases be described? This is not just an empirical question about how such cases are ordinarily described, but also a philosophical question about which theoretical conceptualisation captures the interesting aspects of the cases. One possible description represents the first examples as cases of vertical toleration, i.e. toleration by the state of specific practices among the citizens. The state's reason for this toleration might be described as a form of respect for 
citizens. And the reform examples might be described as a move from respect-based toleration to a purer form of vertical respect by the state for its citizens. I think people sometimes do use the terms 'toleration' and 'respect' in this way, but my question is whether these are theoretically fruitful conceptualisations and what the terms thus used then mean?

According to what I will call the 'standard analyses', toleration and respect are types of relations between different agents. The standard analysis conceptualises toleration to obtain when an agent, the tolerator, dislikes or disapproves of something, e.g. a belief, practice or pattern of behaviour, of another agent; when the tolerator has the power to prevent, suppress or otherwise interfere with the object of dislike or disapproval; and when the tolerator nevertheless refrains from thus interfering. The standard analysis understands respect to obtain when an agent, the respector, has a properly respectful attitude to some other agent and treats the respected agent accordingly.

The noted types of cases seem to have the structure captured by the standard analyses of toleration and respect. The motives for the health campaigns are for instance reasons for objecting to unhealthy life-style choices, which the state could interfere with, but nevertheless tolerates because it respects citizens. And toleration and respect seem theoretically fruitful descriptions since these concept capture aspects of the cases that would be left out if we only said, e.g., that the state permits citizens to live unhealthy lives.

But the conceptualisations of the cases in terms of toleration and respect face a problem: Because the concepts of toleration and respect as usually understood are what I will call attitudinal, the application of these concepts to institutions is problematic, since institutions like the state arguably cannot have attitudes of the required kind. The standard analyses are attitudinal in that they require subjects of toleration and respect to have appropriate types of attitudes towards the objects of toleration or respect. The attitudinal component is necessary to distinguish toleration and 
respect from other related concepts, e.g. to distinguish toleration from indifference, and to distinguish the description of some act or policy as tolerant or respectful from other theoretical descriptions, e.g. in terms of rights or freedom. So what distinguishes toleration and respect from other concepts and make them theoretically fruitful also seems to make them inapplicable to cases involving institutions like the state.

One response is to say that the terms have different meanings as applied to acts of states and of individual persons. Whereas individuals are tolerant or respectful in virtue of their attitudes to one another (horizontally), states are rather thought to be so, e.g., in virtue of upholding rights of citizens (vertically). Application of the attitudinal analyses to states is then a category mistake. But this response comes at a price. It robs the concepts of toleration and respect of their distinctiveness and makes it difficult to capture the important difference between the examples before and after the liberal reforms envisaged above. To do that, we do need something similar to the attitudinal analyses; since the state did not directly interfere or violated rights before the reforms, we cannot rely on understandings of toleration or respect as mere non-violation of rights.

I will therefore investigate whether states can sensibly be described as tolerant or respectful in ways theoretically relevantly similar to the standard analyses. After sketching the standard analyses and the problem of institutional applicability, I suggest that we can make sense of the cases in terms of state toleration or respect if we do not understand the concepts in solely agentcentred (as in attitudinal analyses) or patient-centred (as in explanations of the good of toleration or respect in terms of the effects of being tolerated or respected) ways. We can describe institutions as tolerant or respectful in a sense structurally similar to the standard analyses if we focus on the public features of the relation between states and citizens or groups, without ascribing attitudes in the problematic sense to states. ${ }^{1}$ 
The question about the applicable concepts is of philosophical interest simply as a matter of conceptual clarity and because the applicable concepts in turn reflect back on our conceptualisation of the state. These are descriptive and ontological questions, which do not address the normative question about how the state should act. Different conceptualisations of the statecitizen relation nevertheless lend themselves to different normative views, e.g. whether toleration is normatively significant as a matter of negative freedom, or non-domination, or as a way of securing some kind of public equality? My proposal for a relational reading of political respect and toleration point toward the latter, but I will not enter into the substantive normative debate in this paper. The question concerns the accurate description of the kinds of cases mentioned above, and I will therefore focus on the analyses of toleration and respect as descriptive, i.e. not moralised, concepts (Jones 2007: 394; Nicholson 1985: 161; Newey 1999: 23; Cohen 2004: 69, 84, 95).

\section{The analysis of 'respect'}

'Respect' is used in many different ways. It is often used in a behavioural sense, so that an agent is said to respect me if she treats me in accordance with given constraints or requirements on actions, e.g. if she provides me with assistance or does not steal my property (Raz 2001: 138). This behavioural usage of 'respect' is arguably often used in relation to institutions such as the state; the state is said to respect citizens when it upholds their legal rights.

But this usage of 'respect' makes the concept itself theoretically redundant; one can say exactly the same things about agents conveyed by this usage of 'respect' without invoking the notion of respect, e.g. by only talking about rights and duties. If 'respect' is to contribute with anything of independent significance, it has to denote something more than acting in accordance with given constraints and requirements on action (Darwall 2006: 140). 
Another use of 'respect' includes but goes beyond the behavioural one by also signifying that the constraints or requirements in question are those that people have according to a moral view of them as persons with 'equal dignity' and that rights-respecting action is therefore not merely a requirement of positive law, but of the 'moral law'. This sense of 'respect' signifies that the requirements or constraints have a certain privileged status, e.g. as moral duties.

But even in this justificational sense of 'respect' the term does not add anything to talk about moral rights and duties. Rights-discharge and doing one's duty is not sufficient for respect because respect requires something more than merely doing one's duty (Galeotti, 2010: 80, 84).

What is missing is an additional condition about the actual motivation for the agent's action in conformity with requirements of morality ( $\operatorname{Raz} 2001: 160 \mathrm{ff})$. Respect not only requires action in accordance with the moral law (or the principles of justice) but also that the agent acts out of the moral law (or for the reasons given by the principles of justice). Genuine respect is thus conditional on a fact about the actual motivation of the agent's acting in accordance with requirements of morality; the agent has to be motivated to act by moral reasons (Shockley 2009: 4243). Duty or reasons do not motivate agents in the abstract, so there has to be a fact about the agent that satisfies the motivational condition. This fact is that the agent has a specific evaluative attitude towards the object of respect. This is why respect, according to what I will call the standard analysis, is essentially attitudinal (Bird 2004: 210; Darwall 2006: 120; Dillon 2009; Hill 2000: 64). In addition to doing one's duty, respect also requires a specific attitude of regard towards the beneficiary of the duty and that one does one's duty because one has this attitude (Galeotti 2010: $81,85-86,92)$.

The attitudinal and motivational conditions make respect distinct in a theoretically interesting way that adds something significant not captured by talk of rights or duties. The standard 
analysis of respect therefore specifies these individually necessary and together sufficient conditions for describing an agent or act as respectful:

\section{The standard analysis of respect}

Agent $\mathrm{A}$ respects patient $\mathrm{P}$ with property $\mathrm{O}$ by doing $\mathrm{X}$ iff:

a) The attitudinal condition: $\mathrm{A}$ has an attitude towards $\mathrm{O}$ as being of positive value $\mathrm{V}$;

b) The justificational condition: $\mathrm{V}$ provides $\mathrm{A}$ with reasons $\mathrm{R}$ to do $\mathrm{X}$ in relation to $\mathrm{P}$;

c) The behavioural condition: A does $\mathrm{X}$ in relation to $\mathrm{P}$; and

d) The motivational condition: A does $\mathrm{X}$ because A responds to $\mathrm{R}$.

The attitude involved in respect can be understood in different ways, e.g. as cognitive or non-cognitive states. The present analysis is compatible with different such accounts and only takes 'attitude' to denote a fact about A which is (i) additional to and different from purely behavioural facts about A, (ii) provides A with reasons for action, and (iii) can motivate A to act.

What the appropriate attitude to an object of respect is, i.e. what kinds of attitudes are characteristic of respect, depends on the object of respect and its value. The object of Kantian respect is the individual 'dignity' of persons as such, whereas multicultural respect concerns different kinds of objects, e.g. socially salient forms of collective 'difference' (Bird 2004; Balint 2006: 36). The standard analysis covers both what Stephen Darwall has termed 'appraisal respect', an evaluation that admits of degrees and can be earned and lost, and 'recognition respect', which is categorical and not dependent on merit or desert. The attitude characterising recognition respect is often characterised as 'a way of valuing someone intrinsically' (Darwall 2006: 126; Shockley 2009: 41-43). A somewhat broader formulation is that it is 'a pro-attitude' involving both 'an attitude and a corresponding feeling of regarding others as moral partner' (Galeotti 2010: 88-89). 


\section{The analysis of 'toleration'}

'Toleration' is likewise used to denote a range of quite different patterns of action. If toleration is to be an analytically useful concept, some degree of revision is therefore inevitable and desirable. Everyday uses of 'toleration' are concerned with how people relate to differences and take toleration to consist in at least not interfering with these differences. To make the concept more precise and distinguish toleration from other ways of relating to differences a number of further conditions are needed. To accommodate established conceptual intuitions that 'toleration' denotes 'putting up with' unwelcome and disagreeable differences, to include classic paradigm examples of toleration such as religious toleration in $17^{\text {th }}$ century Europe, and to capture the normatively interesting features of toleration as a way of dealing with conflicts, most theorists of toleration take it to requires the presence of a negative attitude to differences (e.g. Nicholson 1985; 160; Weale 1985: 18; Horton 1996: 32; Newey 1999: 21; Galeotti 2002: 20-21; Forst 2003: 72; Cohen 2004: 88).

A further commonly accepted condition is that tolerators must have (or believe themselves to have) the power to actually interfere with the object of toleration (e.g. Nicholson 1985: 160; Weale 1985: 18; Newey 1999: 31-32; Forst 2003: 72-73; Cohen 2004: 93-94). This condition is necessary to distinguish toleration from non-interference due to resignation or powerlessness.

Finally, toleration requires that the disposition to interfere with the object of the negative attitude is halted by another attitude which, although not cancelling out the negative attitude, outweighs it in the particular case or type of case (Newey 1999: 27; Forst 2003: 72). Such a 'reason for non-intervention' (Newey 2001: 316) arguably has to be intentional and perhaps even 
principled (Cohen 2004: 79-84) in order for toleration to be distinguished from non-interference out of oversight or laziness.

Theorists usually assume very specific relations to obtain between these standard conditions that are often left implicit. It is not sufficient for toleration that an agent has a negative attitude towards something, has the power to interfere with it, and does not do so; it is furthermore required that the negative attitude disposes the agent to interfere so that she would (try to) do so in the absence of the further reason for non-intervention, and thus that the reason for non-interference is the tolerator's effectively motivating reason. I therefore suggest that the standard analysis has to be formulated with a number of further conditions arguably normally assumed but left implicit:

\section{The standard analysis of toleration}

Agent A tolerates patient $\mathrm{P}$ with property $\mathrm{O}$ iff:

a) The negative attitudinal condition: $\mathrm{A}$ has an attitude towards $\mathrm{O}$ as being of negative value V1;

b) The dispositional condition: A's negative attitude towards $\mathrm{O}$ disposes $\mathrm{A}$ and/or provides A with reasons $\mathrm{R} 1$ to do $\mathrm{Y}$ to $\mathrm{P}, \mathrm{Y}$ being an act of extermination, suppression, prevention or otherwise interference with $\mathrm{O}$;

c) The power condition: $\mathrm{A}$ is able to, or believes herself able to, do $\mathrm{Y}$;

d) The positive attitudinal condition: A has an attitude towards $\mathrm{P}$ as being of positive value $\mathrm{V} 2 ;^{2}$

e) The justificational condition: V2 provides A with reasons $\mathrm{R} 2$ not to do $\mathrm{Y}$ to $\mathrm{P}$;

f) The behavioural condition: A refrains from doing Y to P; and

g) The motivational condition: A refrains from doing $\mathrm{Y}$ because A responds to R2. 
Even though toleration is a more complicated relation than respect, since there are two sets of attitudes and derived reasons in play rather than just one (Horton 1996: 32), these additional conditions are quite similar to those in the standard analysis of respect. Conditions a, b, d, e and g thus all refer to attitudinal facts about the agent.

\section{The problem of institutional applicability}

Because both analyses require ascription of attitudes to tolerating or respectful agents, the concepts thus defined cannot apply to agents without attitudes. In cases concerning how modern states relate to citizens it is problematic to say that the state is tolerant or respectful given the standard analyses.

The problem is that modern states are not the kind of entities that can have the required kinds of attitudes (Jones 2007: 387; Heyd 2008: 179; Balint 2012). The modern state is a specific kind of complex political institution constituting a social order distinct from both the people it governs and the personnel that staffs it. States are complexes of institutionally defined roles that are centrally organised, differentiated from other institutions, and endure over time irrespective of changes in personnel or population. States claim authority over a territory, a monopoly of force to be able to enforce this authority, and autonomy from other states (Morris 2004). On this institutionalist understanding of states, they are public systems of rules prescribing and prohibiting certain actions which are regularly complied with in accordance with a public understanding of the system of rules defining the institution (Rawls 1999: 47-48).

The institutionalist understanding of the state implies that it is distinct from both the population, the territory, and from other institutions within society. The question whether the state is tolerant or respectful is therefore different from the question whether 'society' is tolerant or respectful; this might be a question about whether people in society are generally tolerant or respectful, whereas my question is about whether a specific institution can be tolerant or respectful. 
The state is primarily defined by its coercive mode of operation and organisation as a hierarchically organised institution able to make decisions and act on them. Decisions are taken in accordance with institutional procedures, expressed in public laws, rules and directives, and executed by public officials. The state can only act because individuals act in accordance with the rules and procedures defining the state. But acts by individuals in their capacities as representatives or agents of the state gain a new meaning because of the institutional roles and the rights, duties and powers the institution confers on them. The resultant actions must be explained and judged with reference to the institution.

Decisions taken by the state, and hence its actions, may be responsive to reasons. This merely means that individuals acting in accordance with the rules can legitimately act in response to reasons and that the resultant acts of the state can therefore correspond to reasons. But state actions arguably cannot be expressions of attitudes of the required kind. The individuals taking part in the decision making procedures, e.g. members of parliament, government ministers, judges and administrators, have attitudes. One may therefore talk of toleration within these decision procedures (Jones 2007: 385). But this is, then, toleration by individual political actors, not toleration by the state, since the attitudes involved are not the state's attitudes. The decision making procedures direct the actions of the state, but they do not by some stroke of magic transfer attitudes from individuals to the state. $^{3}$

One might object that there are ways in which the state might have attitudes even on this institutionalist understanding. Respectful or tolerant attitudes can be written into the constitution, which is part of the rules defining the state. But such statements are, firstly, expressions of attitudes rather than havings of attitudes (something I will return to below) and, secondly, are more plausibly interpreted as expressions of what the drafters saw as justifications or aspirations for the state. Another possibility is that governments might have attitudes and be the 
privileged representatives of states at any given time. So even though states subsist through changes in government, when a government is in power, its attitudes are the attitudes of the state. But, first, it is not clear why the attitudes of the state should be identified with those of the government rather than, e.g., the parliament or judiciary; and secondly, governments are not identical to the state but have a specific institutional function within the state's decision making and executive procedures. Government actions are not acts of the state but acts to make the state act in specific ways (analogous to military commanders' orders in relation to the military's acts). Even if the government has attitudes, these are not the state's attitudes, and even if they are expressed in acts of government these acts can fail to direct the state as intended (e.g. if ruled unconstitutional) and are even if successful distinct from the resultant acts of the state.

The problem of institutional applicability is distinct from two other problems. First, it is not an epistemological problem concerning whether we can know what the attitudes of the state are but a metaphysical problem concerning the nature of the state and with whether such institutional entities can have attitudes of the required kind.

A second problem concerning applicability of the attitudinal analyses, especially the analysis of toleration, has to do with whether it is legitimate for the state to have and act on the negative attitudes required for toleration. One version of this normative problem is based on the requirement that legitimate states must be neutral (Newey 1999: 123-24; Heyd 2008: 177-78). If legitimacy requires that the state does not take up any positive or negative stance in relation to its citizens' conceptions of the good, then a legitimate state cannot be tolerant, since toleration requires dislike or disapproval that is ruled out by neutrality. This normative problem is that the analysis of toleration should not apply to states, if they are to be legitimate. The problem I address is rather ontological and says that the concepts of toleration, as well as respect, cannot apply to states, given a specific understanding of what a state $i s$. The ontological problem is broader than the normative 
problem both because it arises irrespectively of which account of legitimacy one assumes, and because it also holds for the standard analysis of respect.

\section{Unsatisfactory responses to the problem}

Given the problem of institutional applicability, there are two possibilities: One is to adopt a nonstandard analysis of toleration and respect in relation to states (e.g. Jones 2007) and/or reserve the standard analyses for individual persons (e.g. Newey 1999). Another is to keep the standard analyses, but to reinterpret them in ways making them applicable to states. I have suggested (although not fully argued) that the former approach leaves us without the conceptual resources to accurately describe the kinds of cases I sketched in the beginning, so I want to explore the latter. So my question is whether we can keep the structural aspects of the standard analyses that make the concepts of respect and toleration thus defined useful for describing the noted types of cases and still avoid the problem of institutional applicability?

I want to reject two versions of the second approach. The first proposal is that, although the state as such cannot have the requisite attitudes, one can talk about political toleration and respect because officials acting on behalf of and as representatives of the state act with some degree of discretion which allows for expression of attitudes (Sabl 2008: 222-23; Galeotti 2010: 92). So the response is that a state can be characterised as tolerant or respectful if its officials have the requisite attitudes and act on behalf of the state in ways expressing these attitudes.

But the undeniable fact that individual state representatives, such as judges, have discretion, which allows for their acts on behalf of the state to be influenced and coloured by their attitudes, does not mean that the resultant acts of the institution that these officials represent involve these attitudes. The attitudes of individual agents might be causally important in determining actions of state agents, and hence explaining how the state acts. But it does not follow from this that 
the action in question can be understood as based on an attitude of the state; if the state does not have any attitudes, the fact that its individual agents have does not change this. If toleration and respect requires certain attitudes, then the state cannot act tolerantly or respectfully even if its individual agents can. Even if the state required all its officials to act respectfully, the act of the state would be one of prescription, which does not amount to having specific attitudes.

Another proposal is to reject the claim that impersonal institutions cannot have attitudes. Even though institutions cannot have attitudes in the same way as individual human persons, we can ascribe attitudes to them in another sense. While institutions do not have firstpersonal attitudes, they can be ascribed the equivalents of such attitudes from a third personal perspective on the basis of their actions and general institutional set-up. To say that an institution has a given attitude would then be equivalent to saying that it behaves in a specific way; the semantic meaning of the notion of an 'attitude' is then given in reductionist terms only referring to behaviour and other features about the institution observable from an outside perspective.

But reductionist ascriptions of attitudes fail to establish that institutions have the kinds of attitudes required by the standard analyses of toleration and respect. The analyses distinguish between attitudinal and behavioural facts about the agent. Each type of fact is a necessary but not sufficient condition for describing an agent as tolerant or respectful. So even if an agent does not interfere with some practice or upholds and protects rights, one cannot conclude on this basis that the agent is tolerant or respectful, since toleration and respect also require the presence of specific attitudes in addition to the behaviour. Furthermore, the standard analyses also require that the attitudes function as the agent's reasons and motives for the conduct. If the ascribed attitude is understood reductively, the justificational and motivational conditions arguably cannot be met, since an agent's behaviour cannot be a reason or function as a motive for the agent's behaviour. 


\section{A relational analysis of political respect}

Toleration and respect are relations. But the standard analyses focus on specific aspects of these relations, namely facts about the subject of toleration or respect: the focus is on the agent's behaviour, attitudes, reasons and motives. Attitudinal analyses are thus agent-centred. Explanations for why toleration and respect may be good or even required in terms of the consequences of toleration on people's freedom (Jones 2007: 389, 398) or of respect on people's self-respect (Benditt 2008) are conversely patient-centred.

My suggestion is that agent- and patient-centred analyses do not exhaust the possibilities for analysis of these kinds of relations: the standard analyses neglect some aspects having to do with the relations as such rather than the relata (agent and patients). The attitudes of agents and the freedom enjoyed by patients are of course relational in the strict sense that attitudes are directed at certain objects and freedom is freedom from certain interferences. But these features may not affect and may be inaccessible to others. What I call relational aspects, are those public aspect of relations that are out in the open, so to speak, and may therefore be known to obtain by others (Christiano 2008:47f). ${ }^{4}$

My suggestion is that it is these relational aspects that matter in relation to cases such as those sketched in the beginning. If we can reinterpret the standard analyses in relational rather than attitudinal terms, we might therefore avoid the problem of institutional applicability in a more satisfactory way than the proposals considered hitherto.

Political respect is important because of its significance for people relating to the state, especially for those over whom it exercises pervasive influence and coercion. What is important to people is the actual behaviour of the state and the general relation in which they stand to it. It is the actions of the state that affects people, e.g. the dispensation of prohibitions, permissions and authorisations. But the relation to the state affects the situation of people more broadly, e.g. in terms 
of vulnerability, domination, security, status and general expectations. These aspects are public and relational rather than internal and agent-centred. Even if internal conditions about attitudes justify and motivate the outwards behaviour of the institution, what matters to people is how these facts about the institution are mirrored and expressed in the public aspects of the relation.

My proposal is that respect is not merely something a state does; respect is something the state publicly displays, so others can see that it is respectful. ${ }^{5}$ In relating to the state, it matters to people not only that the state upholds their rights but also that it publicly expresses the right reasons for doing so. People then stand in a relation to the state which is plausibly characterised as one of political respect in a way relevantly similar to the standard analysis of respect, since it is not merely a matter of the state in fact not violating their rights, but also a matter of how and why it does so. But rather than ascribing attitudes in the sense used earlier to the state as an agent, this characterisation turns on the public aspects of the relation.

So the analysis of political respect should focus on the relational aspects, i.e. the state's public display of respect, e.g. expression of reasons for action that matter. This suggestion qualifies the descriptive nature of the analysis. My claim is that we should focus on public expressions of reasons for action because this is what matters. We are interested in how to describe the cases noted in the beginning because they involve these kinds of relational features. Although this reflects normative concerns, it is not tantamount to a moralisation of the concept of respect, since it is still an open question whether, when, and for what reasons, respect is required.

A relational account might solve the problem of institutional applicability. Even if institutions cannot have the requisite attitudes, they can act on and express reasons for action publicly. So let me propose a relational reinterpretation of the standard analysis of respect, which retains the structural elements of the standard analysis, but do not require respectful agents to have 
attitudes. This retains the attractions of the standard analysis while avoiding the problem of institutional applicability:

\section{A relational analysis of respect:}

Agent A respects patient $\mathrm{P}$ with property $\mathrm{O}$ by doing $\mathrm{X}$ iff:

a) The public valuation condition: A publicly displays that $\mathrm{O}$ has value $\mathrm{V}$;

b) The public justification condition: A publicly states that $\mathrm{V}$ provides A with reasons $\mathrm{R}$ to do $\mathrm{X}$ in relation to $\mathrm{P}$;

c) The behavioural condition: A does $\mathrm{X}$ in relation to $\mathrm{P}$; and

d) The motivational condition: A does $\mathrm{X}$ because A responds to $\mathrm{R}$.

The main difference to the standard attitudinal analysis of respect is the reinterpretation of the attitudinal condition in public terms, which allows states to act respectfully without having attitudes. What matters from the point of view of people relating to the state is rather that the state relates to them in a respectful way, where this is captured by the public treatment of them as having a certain value (e.g. public recognition that they have a certain status and standing as human beings, citizens, or as members of some community such as the nation, and by treatment in accordance with this standing).

The stated view in the public justification condition is a proposition that may be true of states, since states may act in response to reasons in the sense that reasons may play a causal role in its internal decision making procedures. This is why the motivational condition is not amended; in order for the state to act respectfully, the reasons $\mathrm{R}$ still have to be effective and make a difference in the internal decision making procedures of the state. The amended justificational condition and the motivational condition are still necessary in order to distinguish respectful action from mere 
rights-discharge and to ensure that the publicly displayed valuation in the public valuation condition is not merely symbolic in the disparaging sense of this term. A state is not respectful even if it acknowledges the dignity of people if this view (or, rather, the reasons its acceptance gives rise to) does not affect how it treats them; in fact, such a merely symbolic expression of 'respect' would be disrespectful. That is why the amended justificational condition and the motivational condition are still necessary for the analysis of political respect.

The relational solution to the problem of institutional applicability is different from the reductionist solution rejected above in several ways: First, the relational solution does not provide an analysis of what it is or means for an institution to have attitudes; it rather says that what matters is (also) how states publicly express reasons for their actions. Second, institutions' public expressions of reasons for actions are not understood as answers to the justificational and motivational conditions, since expressions of reasons is part of what the institutions do, rather than the reasons or motives for these acts. This is why the public expression of reasons for action is not in itself sufficient for respect; the reasons in question furthermore have to be motivationally effective. This is not a problem if institutions can act in response to reasons, even if they cannot have attitudes. So if what matters in terms of institutional respect are the publicly expressed reasons for action and their effectiveness in the actual decision procedures, a relational analysis can distinguish institutional respect from other concepts such as rights or duties without having to postulate institutional attitudes.

\section{A relational analysis of toleration?}

If my proposed relational conception of political respect as expressed in the relational analysis of respect is acceptable, the problem of institutional applicability of the concept of respect is solved. But if a relational conception of institutional respect is available, so might a relational conception of 
political toleration, which might solve the problem of institutional applicability of the concept of toleration.

Since toleration requires the tolerator to overcome some rejection, dislike or disapproval of what is tolerated, it might be objected that it is difficult to see how the state can at the same time establish certain rules or standards and then 'tolerate' their infringement. But the types of examples provided in the beginning are arguably illustrations of exactly this: the state publicly disapproves of smoking and blasphemy, but does not ban it or refrains from enforcing the ban. My suggestion is that these kinds of cases are best described in terms of toleration, since they precisely seem to instantiate the structural features (the tension between rejection and acceptance) captured by the standard analysis. Non-standard conceptions of toleration that either dispense with the rejection component or locate it outside the state fail to capture these structural features, and the attitudinal standard analysis fails to apply to states. So the philosophical question is in what sense the state nevertheless is tolerant in these cases. If a relational analysis can retain the structural features of the standard analysis while avoiding ascribing attitudes to the state, it can explain this.

A relational analysis of toleration can treat the reasons for toleration (the positive attitudinal condition and the derived justificational and motivational conditions) analogously to the relational analysis of respect, insofar as respect may function as the acceptance component justifying and motivating non-interference. It is more difficult to give a relational and nonattitudinal reading of the reasons for opposition necessary for toleration. So the question is how the state might fulfil the condition of opposition (including the derived dispositional condition) without having negative attitudes? Let me sketch three different ways in which one could formulate a political concept of toleration:

Deflationary conceptions merely drop the negative attitudinal condition and stick with the dispositional condition. What matters is then that the state would interfere in the absence of 
further reasons for toleration (dealt with in a manner analogous to the relational analysis of respect). The reasons for or causes of this disposition need not be attitudes of the state; it might be attitudes of people in government, members of parliament, or a constituency of citizens to whose opinions the state would usually be responsive, e.g. because they form a democratic majority or a powerful interest group.

The deflationary conception makes sense of state toleration while avoiding ascription of attitudes to the state, but it only focuses on the public aspects of the reasons for toleration. The rejection component is not necessarily public, so this conception is not fully relational in the sense sketched above. It might nevertheless be an appropriate conception of state toleration in relation to description of some cases. If the government for instance is controlled by people convinced that homosexuality is sinful and dangerous, their influence will dispose the state to interfere with homosexuality. If there are public limits on the exercise of state power in place, however, the state might at the same time fulfil something equivalent to the reasons for toleration. This is nevertheless different from the reductionist conception discussed earlier, since the addition of the reasons for toleration implying that a tolerant state is responsive to reasons.

Most of the kinds of cases sketched in the beginning require a more fully relational conception. A possibility is expressivist conceptions, which retain something equivalent to the negative attitudinal condition but reinterpret it in terms of publicly expressed valuations in analogy with the public valuation condition in the relational analysis of respect. Although lacking attitudes, a tolerant state would then express negative valuations of certain groups or practices. In order for this public valuation to connect in the right way with action, the state would also have to be disposed to interfere with the objects of the expressed negative valuation. One reason why the state is thus disposed might be that it is responsive to reasons; there might then be a common cause of the 
public expression of negative value and the disposition to interfere, e.g. some form of input to the state's decision making processes that is a potential reason for interference. ${ }^{6}$

Expressivist conceptions of toleration seem to capture several of the cases noted in the beginning involving public statements, e.g. the public health campaigns, or the granting of exceptional leave to remain to rejected applicants for asylum. Deliberate non-enforcement of criminal laws might also be cases of expressivist toleration, e.g. dormant blasphemy ban type cases, if the reasons for non-enforcement, e.g. the greater importance of free speech, are publicly stated.

The problem with the expressivist conception is that the requirement of explicit public valuations is potentially too restrictive. Not all of the cases noted involve explicit statements or public expressions of valuations, and insofar as they are fruitfully described as cases of toleration, which cannot be adequately captured by non-standard analyses of toleration, the expressivist conception does not explain all kinds of relational toleration.

Inferential conceptions address the problem of restrictiveness by inferring something functionally equivalent to an objection component from other features of the state, its laws or its mode of functioning. If a state for instance publicly supports a specific religion by upholding an established church with privileges denied to other religions, one might interpret this as an implicit negative valuation of other religions. If the state nevertheless does not interfere with the practice of other religions, then it might be thought of as tolerant. Inferentially based descriptions of states as tolerant rely on interpretations, e.g. of the relation between state and church, which are controversial and complicated. This might be problematic, since it does not follow from the fact that the state positively supports something (e.g. a religion), that it is opposed to all other things of the same kind (competing religions) in a way providing the objection component necessary for toleration. The inferential conception therefore risks describing too many cases as cases of political toleration. This 
problem requires careful consideration of the justifiability of inferences grounding interpretations of states as being opposed to something.

Although it might be reasonable to infer negative valuations from public features of a state, this is not sufficient for describing the state as tolerant; inferred negative valuations furthermore have to connect with a disposition to interfere, which is then overridden by some reason for toleration, in order for the case to instantiate the structure of the standard analysis of toleration. It is more difficult to justify the ascription of a disposition to interfere within the inferential conception - at least, such a disposition does not follow from an inferred negative valuation. Descriptions of states as tolerant must therefore be based on broader arrays of features of the state, including both public features grounding and possibly less public dispositions like those involved in the dispositional conception, e.g. actual attempts from members of government to use state power to interfere with minority religions, whether or not these are publicly expressed.

\section{Conclusion}

In this paper I have argued that states can be subjects of toleration and respect in ways relevantly similar to the standard analyses of these concepts. Even though states cannot have attitudes in the same way as persons, they can be agents standing in relations to people which are structurally similar to relations of toleration or respect between people. The concepts of toleration and respect thus do not have completely different meanings as applied to states and to ordinary persons.

In arguing this point, I have relied on a number of generic examples of relations between states and citizens, which seem to be cases of vertical toleration, i.e. toleration by the state of citizens. The point of these examples is to show that it is unsatisfactory to merely redefine toleration and respect in terms of non-interference or upholding of rights - this would leave out important aspects of the relations, which are precisely central to the standard analyses of respect and 
toleration. I have therefore proposed a reinterpretation of the standard analyses that retain their structure but understand the attitudinal conditions in relational rather than agent-centred terms. I have finally argued that even though this relational reinterpretation is facing a number of challenges as applied to toleration, there are ways of understanding toleration relationally as well, although different cases might be instances of different conceptions of relational toleration. This plurality is not necessarily objectionable, since all of the conceptions retain the structure of the standard analysis. It merely requires one to specify which conception one applies, which the application of the concept already requires in other respects (e.g. the contextual specification of power and interference).

Although my discussion relates to ontological questions about what states are and normative concerns with how states should relate to their citizens, it has been conceptual. The question has not been the ontological one whether states can be tolerant or respectful, but the conceptual one about in what sense they can be. My relational answer points towards the normative level, but it is not prescriptive. I have not claimed that states should publicly display the reasons for respecting citizens or that it is legitimate for states to act publicly in ways expressing negative valuations (although it might be). I have rather suggested that the public aspects of the relationship between states and citizens in the types of cases noted in the beginning matter to citizens, and that the structure of respect and toleration characterising such cases therefore should be understood relationally rather than agent-centred. These cases can then be described in terms of toleration and respect in ways that capture the aspects of them that are normatively engaging. This description does not in itself say what states should do, it merely conceptualises the relationship in terms highlighting normatively significant features. ${ }^{7}$

\section{Sune Lagaard}


Department of Culture and Identity

Roskilde University

Universitetsvej 1

P.O.box 260

DK-4000 Roskilde

Denmark

laegaard@ruc.dk

\section{References}

Balint, P. (2006), 'Respect Relationships in Diverse Societies', Res Publica, 12: 35-57.

Balint, P. (2012), 'Not Yet Making Sense of Political Toleration', Res Publica, 18, doi:10.1007/s11158012-9177-3

Benditt, T.M. (2008), 'Why Respect Matters', The Journal of Value Inquiry, 42: 487-496.

Bird, C. (2004), 'Status, Identity, and Respect', Political Theory, 32: 207-232.

Christiano, T. (2008), The Constitution of Equality: Democratic Authority and Its Limits. Oxford: Oxford University Press.

Cohen, A.J. (2004), 'What Toleration Is', Ethics, 115: 68-95.

Darwall, S. (2006), The Second-Person Standpoint: Morality, Respect, and Accountability. Cambridge, Ma.: Harvard University Press. 
Dillon, R.S. (2009), 'Respect', in E.N. Zalta (ed.) The Stanford Encyclopedia of Philosophy (Winter 2009 Edition). http://plato.stanford.edu/archives/win2009/entries/respect/

Forst, R. (2003), ‘Toleration, Justice and Reason', in C. McKinnon and D. Castiglione (eds) The Culture of Toleration in Diverse Societies: Reasonable Tolerance. Manchester: Manchester University Press.

Galeotti, A.E. (2001), ‘Do We Need Toleration as a Moral Virtue?’ Res Publica, 7: 273-292.

Galeotti, A.E. (2002), Toleration as Recognition. Cambridge: Cambridge University Press.

Galeotti, A.E. (2010), 'Respect as Recognition: Some Political Implications', in M. Seymour (ed.) The Plural States of Recognition. Basingstoke: Palgrave.

Heyd, D. (2008), 'Is Toleration a Political Virtue?' in M.S. Williams and J. Waldron (eds) NOMOS XLVIII: Toleration and Its Limits. New York: New York University Press.

Hill, Jr., T.E. (2000), Respect, Pluralism, and Justice: Kantian Perspectives. Oxford: Oxford University Press.

Horton, J. (1996), ‘Toleration as a Virtue', in D. Heyd (ed.) Toleration: An Elusive Virtue. Princeton: Princeton University Press.

Jones, P. (2007), 'Making Sense of Political Toleration', British Journal of Political Science, 37: 383-402.

Jones, P. (2012a), ‘Toleration, Religion and Accommodation', European Journal of Philosophy, DOI: 10.1111/j.14680378.2012.00549.x

Jones, P. (2012b), 'Legalising Toleration: a Reply to Balint', Res Publica, 18, DOI: 10.1007/ s11158-012-9178-2. 
List, C. and P. Pettit (2011), Group Agency: The Possibility, Design, and Status of Corporate Agents. Oxford: Oxford University Press.

Morris, C. (2004), 'The Modern State', in G. Gaus and C. Kukathas (eds) The Handbook on Political Theory. London: Sage Publications.

Newey, G. (1999), Virtue, Reason and Toleration. Edinburgh: Edinburgh University Press.

Newey, G. (2001), 'Is Democratic Toleration a Rubber Duck?’ Res Publica, 7: 315-36.

Nicholson, P. (1985), 'Toleration as a Moral ideal', in J. Horton and S. Mendus (eds) Aspects of Toleration. London: Methuen.

Rawls, J. (1999), A Theory of Justice. Revised edition. Cambridge, Mass.: Harvard University Press.

Raz, J. (2001), Value, Respect, and Attachment. Cambridge: Cambridge University Press.

Sabl, A. (2008), "'Virtous to Himself”: Pluralistic Democracy and the Toleration of Tolerations', in M.S. Williams and J. Waldron (eds) NOMOS XLVIII: Toleration and Its Limits. New York: New York University Press.

Shockley, K. (2009), 'Practice Dependent Respect', The Journal of Value Inquiry, 43: 41-54.

Weale, A. (1985), 'Toleration, Individual Differences and Respect for Persons', in J. Horton and S. Mendus (eds) Aspects of Toleration. London: Methuen.

\footnotetext{
${ }^{1}$ My argument has a similar structure to that in Jones (2012a). Jones focuses on cases of exemptions which 'might also seem to have the classic structure of a tolerated condition' (2012a: 10). He then notes a problem in this description, namely to identify the tolerator. He therefore proposes to reinterpret political toleration: 'the problem of identifying a tolerator arises from use of the person-to-person model of toleration. Rather than viewing exemptions according to that
} 
model, we would do better to see them as representing a society's public stance on what should and should not be tolerated. Toleration is a feature of the exemptions themselves rather than an expression of any particular person's or party's toleration.' (2012a: 10) My argument differs from Jones's in that I think it is possible to identify a tolerator, namely the state as an institutional entity. I diagnose a different problem, namely that states thus understood cannot be subjects of toleration in the attitudinal sense. I therefore propose to reinterpret the standard analysis of toleration in relational terms. But despite these differences in content, our arguments make analogous argumentative moves. ${ }^{2}$ Actually, the object of the positive attitude constituting the acceptance component need not be identical to the object of the negative attitude constituting the objection component; I may object to your behaviour but tolerate it out of concern for your mother's feelings or out of self-interest. I nevertheless stick with the two person formulation for the sake of presentational simplicity.

${ }^{3}$ List and Pettit (2011) argue for the possibility of aggregating individual attitudes into group attitudes. I am not able to discuss their sophisticated theory here. What I have been saying earlier tallies with their idea of group agency as compatible with methodological individualism and of states as group agents $(2011: 4,40)$. I nevertheless resist talk of states as having attitudes, partly because of the attitude/act distinction (decisions, e.g. in parliaments, concern acts, not attitudes), partly because I am unsure about whether aggregated attitudes can have the causal status required of motives of respecting and tolerating agents, partly because I see my own relational alternative as in line with their 'performative' conception of corporate personhood (2011: 171-72).

${ }^{4}$ What I call a relational analysis of is different from what Peter Jones (2012b) calls a 'third-party' perspective. This is the perspective that democratic citizens take up when deliberating over the sort of toleration that ought to obtain amongst the members of their society and which rules and arrangements ought to be enacted to enforce this. Since it is a justificational perspective, it is distinct from actual relations of toleration - both vertical toleration (i.e. the toleration by the state that I am concerned with) and the horizontal toleration among citizens.

${ }^{5}$ My proposal is partly analogous to Christiano's claim that publicity is a crucial component in justice; justice must not only be done, it must be seen to be done (Christiano 2008). But where Christiano's idea of publicity is a constraint on normative principles restricting their possible content my idea is that publicity is relevant to the concept of political respect. So the corresponding publicity constraint does not directly set limits on how institutions should behave (this is a further, normative question) but on when we can sensibly describe them as behaving respectfully (in ways that matter). 
${ }^{6}$ One complication here is that states are not entirely unitary; even though centrally organised, states consist of different organs which might express different views. This complication might be dealt with by specifying whether it is the state as such or a specific branch of the state that is tolerant.

${ }^{7}$ Versions of this paper have been presented at the ethics research group at Roskilde University, at the RESPECT project workshop on Toleration, Respect and Space at the University of Copenhagen, at the Manchester Workshops in Political Theory, and at the ECAP 7 Seventh European Congress of Analytic Philosophy in Milan. Thanks to Peter Balint, Magali Bessone, Ian Carter, Emanuela Ceva, Phil Cole, Achilles Emilianides, Jakob Holtermann, Nils Holtug, John Horton, Peter Jones, Graham Long, Tariq Modood, Morten Ebbe Jull Nielsen, Thomas Søbirk Petersen, Enzo Rossi, Jesper Ryberg, Frej Klem Thomsen, Daniel Weinstock, Federico Zuolo and anonymous reviewers for the EJP for comments. The research informing the paper was supported by the European Commission, 7th Framework Program, project RESPECT (GA no. 244549). 